\title{
Certain new aspects of etiology and pathogenesis of Alzheimer's disease
}

\author{
Ivan V. Maksimovich
}

Clinic of Cardiovascular Diseases Named after Most Holy John Tobolsky, Moscow, Russia; carvasc@yandex.ru

Received 18 October 2012; revised 20 November 2012; accepted 29 November 2012

\section{ABSTRACT}

The research focuses on the possibility of early detection of AD-specific vascular and atrophic brain changes in families which have a tendency to inherit the disease. The research included three families with AD inheritance. All patients underwent: cognitive function assessment (MMSE), determination of dementia severity (CDR) and $A D$ stages (TDR), computed tomography (CT), magnetic resonance imaging (MRI), scintigraphy of the brain (SG), rheoencephalography (REG), and cerebral multi-gated angiography (MUGA). All patients with different $A D$ stages, as well as their descendants, have specific atrophic changes in the temporal lobes of the brain. The degree of these changes increases as $A D$ becomes more severe and ranges from $4 \%-8 \%$ (TDR-0) to $33 \%$ $62 \%$ (TDR-3) of the total mass of a healthy person's temporal lobes. Simultaneously, the patients examined have changes of microcirculation manifested by reduction of the capillary bed in the temporal and frontalparietal regions, the development of multiple arterio-venous shunts in the same areas, early venous dumping, anomalous expansion of venous trunks that receive blood from the arterial-venous shunts, venous stasis on the fronto-parietal boundary. Similar changes are found among AD patients' descendants aged 8 - 11, the only difference being in the degree of temporal lobes atrophy which is 4.7\%. This proves that microcirculatory disorders are primary and atrophic changes of the temporal lobes are secondary in AD development. The data obtained indicate that the examination of AD patients' relatives should begin well before the possible manifestations of the disease, even in childhood. It will allow to reveal the possibility of inheritance and the signs of the disease at the earliest possible stage and to begin its treatment in time.
Keywords: Alzheimer's Disease; CDR; TDR; Dementia; Vascular Factors in Alzheimer's Disease; Dyscirculatory Angiopathy of Alzheimer's Type; DAAT; Hippocampus; Temporal Lobes Atrophy

\section{INTRODUCTION}

Alzheimer's disease (AD) was discovered more than a hundred years ago. In spite of this, the etiology and pathogenesis of the disease, as well as the timing of the primary changes occurring in the brain, are not fully understood. According to the Alzheimer's Association, there were 35.6 million people suffering from this disease worldwide in 2010. By 2050 this figure is expected to exceed 115 million [1]. Life expectancy is constantly increasing, and as a result every other inhabitant of the planet at the age of 85 and older will suffer from AD [2].

It is known that certain chemical changes in the brain occur 10 - 20 years before the primary clinical manifestations of the disease during sufficiently rare, genetically determined $\mathrm{AD}$ forms [3]. With sporadic AD, primary changes in brain tissue also develop long before the clinical symptoms but the manifestation of these changes is low [4]; this form is also characterized by inheritance of the disease.

For many years, AD was seen as only a neurodegenerative disease and its research focused on the study of morphological, histological, histo and cytochemical changes that occur in the brain. The research was mostly based on the material obtained from patients with latestage AD [5-8].

Clinically, the severity of dementia in AD was determined with the classification proposed by J. C. Morris in 1993 (The Clinical Dementia Rating/CDR/) [9]. Evaluation of the patients' cognitive impairment and mental state was often carried out by means of Mini-mental State Examination (MMSE) [10].

A great step in the study of AD was lifetime research by means of CT and MRI which allowed identifying atrophic changes developing in the hippocampus, temporal and fronto-parietal brain regions $[11,12]$. But these studies were also often performed during $\mathrm{AD}$ late sta- 
ges with the severity of dementia equal to CDR-2, CDR3 [9]. In recent years, the question of structural changes in the brain during AD early clinical stages accompanied by Mild Cognitive Impairment (MCI) [13-15] and during its pre-clinical stage [16-20] has begun to be studied.

Further application of PET and biomarkers has allowed the development of highly advanced methods of visualization of amiloid-beta and tau accumulation as the main features of neurodegenerative process during AD. Currently, these methods are being worked on; they require further study and standardization [21-24]. However, it has been discovered that in some cases the high levels of amyloid in the brain do not always lead to the development of dementia and AD [25]. Besides, the research conducted with Abeta42 immunisation has shown the possibility to remove amyloid from the brain tissue, but it has not led to any significant regression of neurodegeneration or dementia decline [26].

In the $1930 \mathrm{~s}, \mathrm{~F}$. Morel was the first to reveal the pathological changes that occur in the vascular system of the brain in the development of AD which he named dysoric or drusoidal angiopathy [27]. But as AD was seen as a neurodegenerative disease, insufficient attention was given to the problem of the circulatory system of the brain, disorders of its blood supply and hemodynamics. Moreover, the correlation of vascular and degenerative changes that occur in the brain and their combined influence on the development of dementia and cognitive disorders were not considered [16,18,28,29].

Serious work dedicated to the vascular factor in the development of AD has appeared only recently [30-32]. It can be divided into three areas: the impact of extraneous factors, such as hypertension, hyperlipidemia, atherosclerosis, diabetes, cardiac arrhythmia, on AD development [33-37]; amyloid angiopathy in the development of $\mathrm{AD}[38,39]$; degenerative vascular changes occurring in the brain in the development of AD [17-19,28,29,40-47]. It must be mentioned that there is a strong possibi- lity that these factors may act together and influence the development of the disease [48-50].

The greatest difficulty in determining the signs of the disease lies in identifying the earliest changes that occur in the brain and could indicate a possible development of $\mathrm{AD}$ in the future. Clinically, these changes are impossible to be identified as there are no signs of the disease; symptoms of dementia or cognitive impairment are either absent or very weak. The scarce symptoms are difficult to distinguish from the norm or from pathological manifestations of other processes [18,29].

Given a sufficiently high probability of inheritance of not only genetically determined but also of sporadic AD, the diagnosis of both clinical and preclinical AD stages among relatives has been considered in our earlier works $[18,19,29,51]$.
83 patients were examined. The examination of 72 patients with clinical AD stages (CDR-1-CDR-3) revealed atrophic changes in the temporal lobes of the brain amounting to $9 \%-62 \%$ of the total mass of temporal lobe tissue depending on AD stage [29,52]. Consequently, we developed a special scale for determining the stages of dementia in AD based on the severity of atrophic changes in the temporal lobes of the brain identified during CT or MRI. We named this scale "The Tomography Dementia Rating Scale" (TDR) [52].

Certain specific vascular disorders were revealed among these patients. The disorders are manifested in the reduction of the capillary bed in the temporal and frontalparietal regions of the brain, the development of multiple arteriovenous shunts in the same regions, the development of venous dumping in the same regions, venous stasis with the formation of abnormal venous trunks receiving blood from the temporal and fronto-parietal regions, and the large looping of distal branches of intracranial arteries. We named these changes "The Dyscirculatory Angiopathy of Alzheimer's Type” (DAAT) [29, 53].

A group of AD patients' relatives were also examined during the research. The group included 11 fairly young people aged from 34 to 42 who had not been diagnosed with AD but who had growing memory disorders without manifestations of dementia or any specific cognitive disorders; $9(81.82 \%)$ of them had atrophic changes in the temporal brain regions with the tissue mass reduced by $4 \%-8 \%$. We regarded this group as preclinical AD stage or as a group with a high probability of $A D$ inheritance. For these patients a zero degree of dementia was introduced-TDR-0 [52]. This group of patients also had specific vascular disorders similar to those that were identified among their relatives suffering from AD [53, 54].

It should be noted that if the atrophic changes in the temporal lobes increased with the growing severity of dementia, DAAT observed among all 83 patients had a similar degree regardless of their TDR stage [29,53].

This research focuses on the possibility of early detection of AD-specific vascular and atrophic brain changes in families which have a tendency to inherit the disease.

\section{METHODS}

\subsection{Patient Selection}

The whole research has been carried out with the approval of the Ethics Committee, as well as with the consent of the examined patients and their relatives.

Three families with AD inheritance have been examined:

- 3 elderly people aged from 66 to 75 who were previously diagnosed with $\mathrm{AD}$, including 1 with a mod- 
erate form of dementia (TDR-2) and two with a severe one (TDR-3) and a medical history of the disease of 6 - 12 years.

- 2 their sons and 1 daughter aged from 40 to 46 who were previously diagnosed with $\mathrm{AD}$ with early manifestations of the disease, mild dementia (TDR-1) and a medical history of 2 years.

- 3 their grandchildren aged from 8 to 11 who complained of memory loss, difficulties in remembering and concentrating, fatigue and frequent headaches.

\subsection{Patient Examination}

Patient examination included:

- AD patients' cognitive function was assessed by the Mini-Mental State Examination (MMSE) [10].

- AD patients' dementia severity was clinically determined by the Clinical Dementia Rating scale (CDR) [19].

- AD stages were determined tomographically, in accorance with the Tomography Dementia Rating scale (TDR) [52] during CT and MRI examination.

- Laboratory examination was performed according to generally accepted interventional cardiology schemes and included coagulological, biochemical and general clinical examination.

- Scintigraphy of the brain (SG) was carried out on a gamma camera (Ohio Nuclear, U.S.) following the classical method in dynamic and static modes using TC 99M pertechnetat 555.

- Rheoencephalography (REG) was performed using "Reospektr-8" (Neurosoft, Russia) in accordance with the standard automated method determining pulse volume abnormalities in the hemispheres of the brain.

- CT and MRI of the brain were conducted on "Hi Speed" (GE), "Tomoscan" (Philips), "Apetro Eterna"

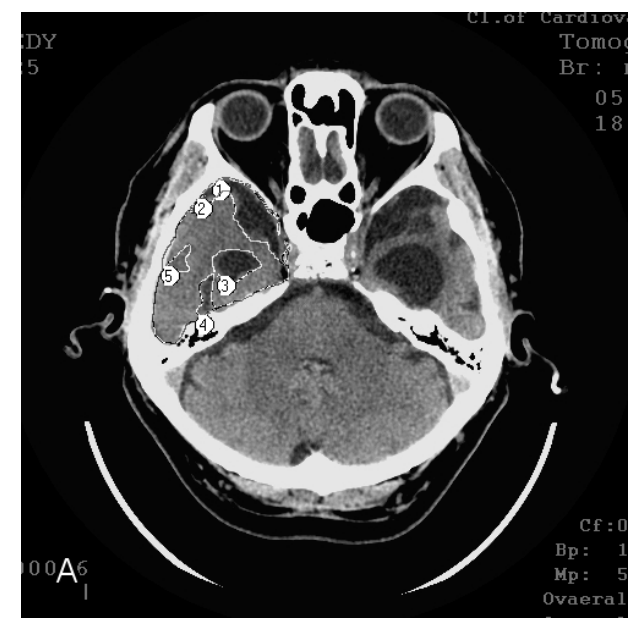

(a)
(Hitachi) following the method which allows the determination of the volume of the temporal lobes of the brain and subsequent detection of the degree of atrophy as a percentage of total tissue weight of a normal temporal lobe [16-19,29,52].

- Cerebral multi-gated angiography (MUGA) was performed on "Advantx" (GE) following the classical method of transfemoral access. Simultaneously, taking into account the start and the speed of the injecttion, 10 - $12 \mathrm{ml}$ of Omnipack 350 was introduced intra-carotidally and $7-8 \mathrm{ml}$ intra-vertebrally. The registration was carried out in direct and side projecttions in constant subtraction mode at a speed of 25 frames per second. Further on the angiograms obtainned in each phase of contrast were analysed frame by frame $[16,19,29]$. Analysis of capillary density was performed in the appropriate phase with an automatic method by means of the computer program "Angio Vision" based on determining the degree of blackening of the corresponding image section of the brain $[53,54]$.

\section{RESULTS}

\subsection{Tomographic Examination Data}

CT and MRI among all adult patients suffering from $\mathrm{AD}$ revealed certain objective characteristic morphological changes of the brain (the results are illustrated by an example of family S.):

- Late AD stage-severe dementia TDR-3 (2 elderly patients): temporal lobes atrophy with $33 \%-62 \%$ reduction of tissue mass which corresponds to $7-11$ MMSE points (Figures 1(a) and (b)).

- Middle AD stage - mild dementia TDR-2 (1 elderly patient): temporal lobes atrophy with $19 \%$ - 32\% re-

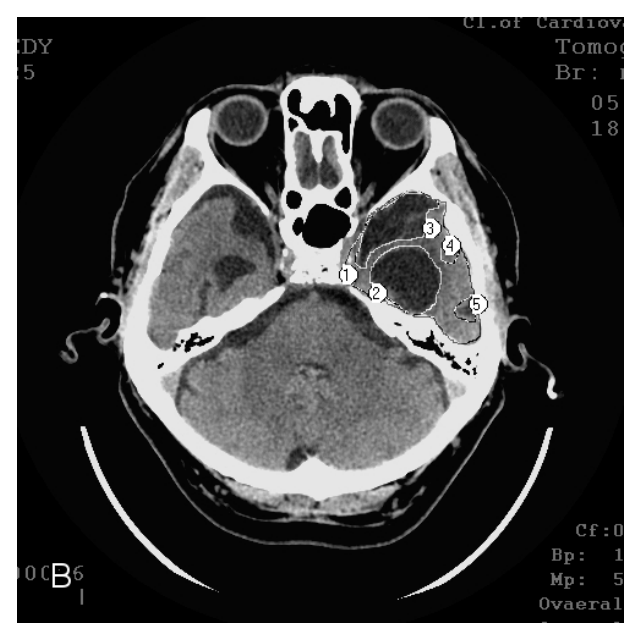

(b)

Figure 1. CT, patient S., 67 years old, (TDR-3) grandfather. Tissue mass reduction: (a) of the right temporal lobe $-41 \%$ (area $1-5$ ); (b) of the left temporal lobe $-62 \%$ (area $1-5$ ). 
duction of tissue mass which corresponds to 12 - 19 MMSE points.

- Early AD stage - mild dementia TDR-1 (2 sons and a daughter): temporal lobes atrophy with $9 \%-18 \%$ reduction of tissue mass which corresponds to 20 - 25 MMSE points (Figures 2(a) and (b)).

Children examination in all cases showed signs of hypotrophic changes in the temporal lobes with $4 \%-7 \%$ reduction of tissue mass (Figure 3). It should be noted that these changes are more marked in the lower parts of the temporal lobes. The degree of these changes lessened in upper regions, so $4.7 \%$ is an average value of hypotrophy of tissue mass of the entire lobe.

\subsection{Functional Examination Data}

All the patients regardless of age had a slowing of blood flow in the cerebral hemispheres during SG.

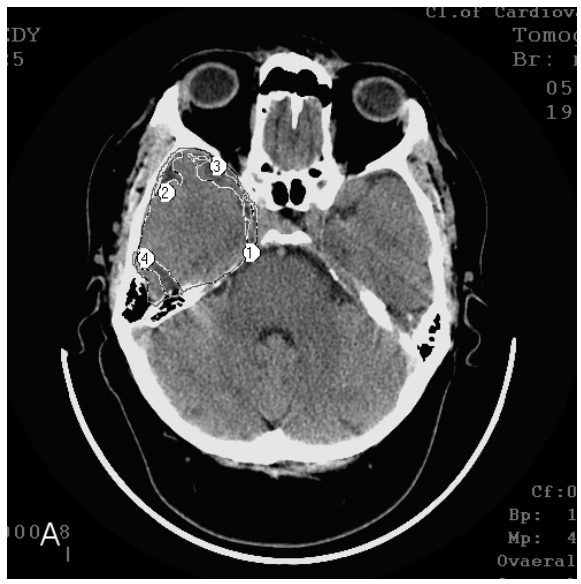

(a)
All the patients regardless of age had a decrease in the volume of pulse blood supply in the carotid basins during REG.

\subsection{Angiographic Examination Data}

Cerebral MUGA showed (the results are illustrated by the example of the same family S.):

- Reduction and depletion of the capillary bed in the form of microvascular sites in the projection of the hippocampus and frontal-parietal regions were observed among all patients (Figures 4(a), 5(a) and 6(a));

- Multiple arteriovenous shunts in the basin of arterial branches supplying the frontoparietal regions of the brain and in the basin of the frontal villous artery supplying the hippocampus, accompanied by early venous dumping with simultaneous filling of arteries and veins, were observed among all patients exam-

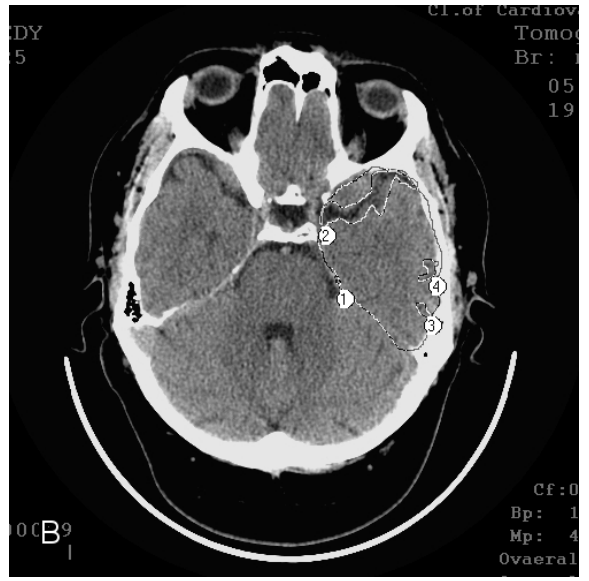

(b)

Figure 2. CT, patient S., 42 years old. (TDR-1) son. Tissue mass reduction: (a) of the right temporal lobe $-18 \%$ (area 1 - 4); (b) of the left temporal lobe $-17 \%$ (area 1 - 4);

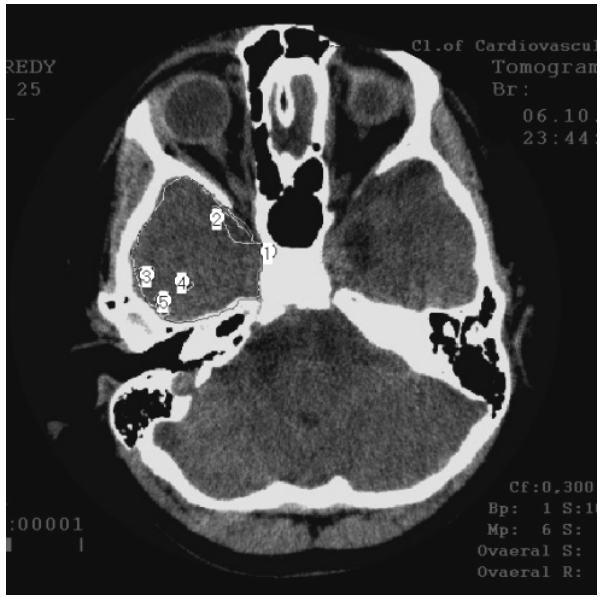

(a)

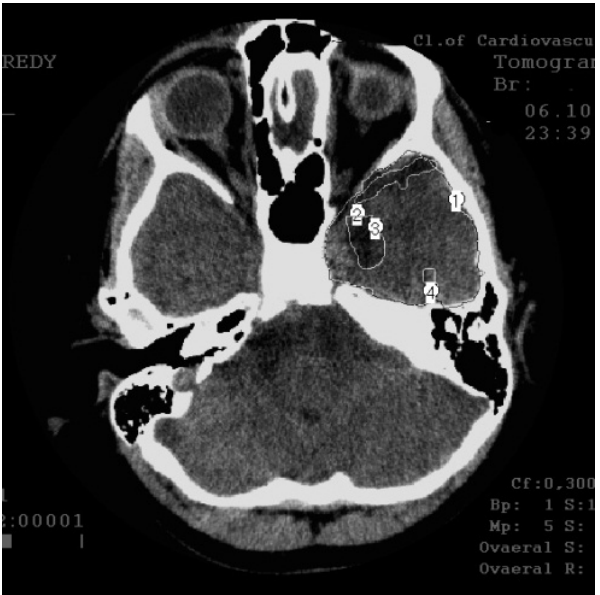

(b)

Figure 3. CT, patient S., 10 years old (grandson). Tissue mass reduction: (a) of the right temporal lobe $-5 \%$ (area 1 - 5); (b) of the left temporal lobe $-16 \%$ (area 1 - 4). (Average hypotrophy of temporal lobes $4 \%-7 \%$ ). 
ined (Figures 4(a) and (b), Figures 5(a) and (b), Figures 6(a) and (b));

- Development of abnormally enlarged lateral venous branches receiving blood from arteriovenous shunts in the temporal and fronto-parietal regions was observed among all patients examined (Figures 4(a), 5(a) and 6(a));

- Abnormal venous stasis at the boundary of the frontal and parietal lobe was observed among all patients examined (Figures 4(b), 5(b) and 6(b));

- Increased looping of distal intracranial arterial branches was observed among all patients examined (Fig-

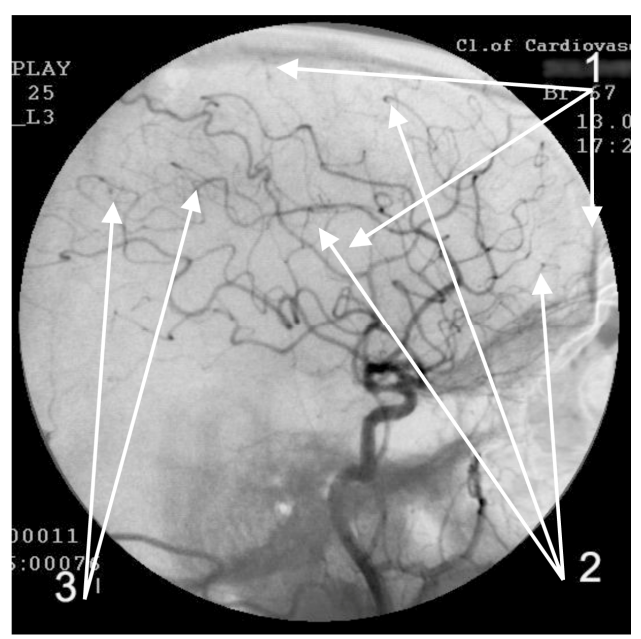

(a) ures 4(a), 5(a) and 6(a)), although it was somewhat less pronounced among children.

Thus, the manifestations of the dyscirculatory angiopathy of Alzheimer's type (DAAT) were detected in all patients examined, regardless of their age and whether they are affected by AD or are descendants of AD patients.

Atrophic changes in the tissue of the temporal lobes of the brain were also found among all patients examined, but there is a difference here: the changes are pronounnced among patients suffering from $\mathrm{AD}$ and increase with growing severity of the disease, whereas they are at

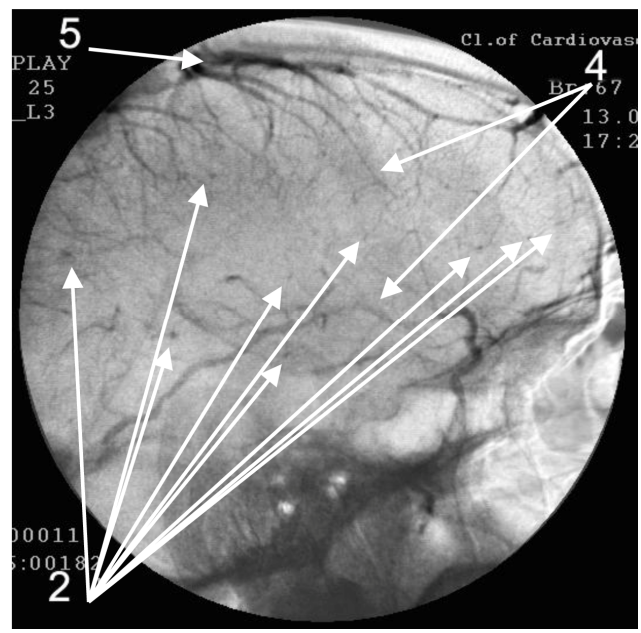

(b)

Figure 4. Angiogram of the left internal carotid artery of patient S., 67 years old (grandfather); lateral projection, (a) arterial phase; (b) venous phase. 1: Development of hypovascular region; 2: Multiple arteriovenous shunts in frontoparietal and temporal regions; 3 : Multiple loop formation; 4: Development of anomalous venous trunks in the frontoparietal region; 5: Development of congestion on the boundary of the frontoparietal region.

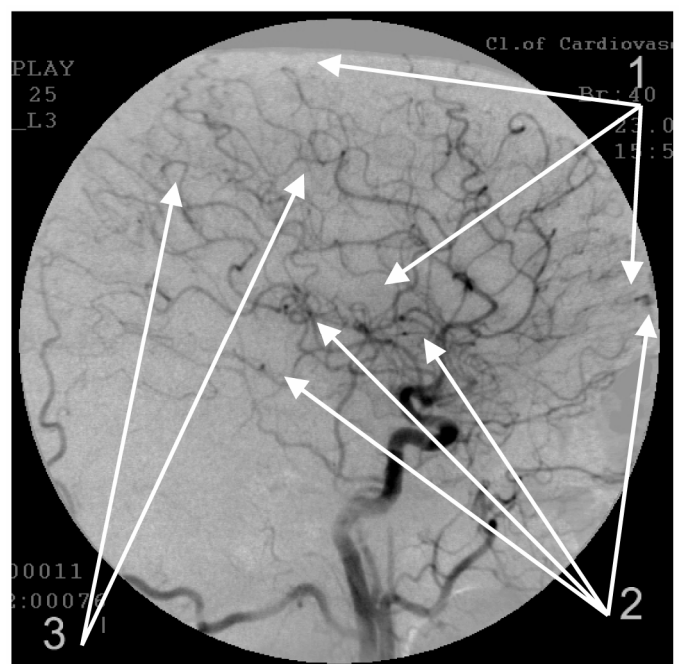

(a)

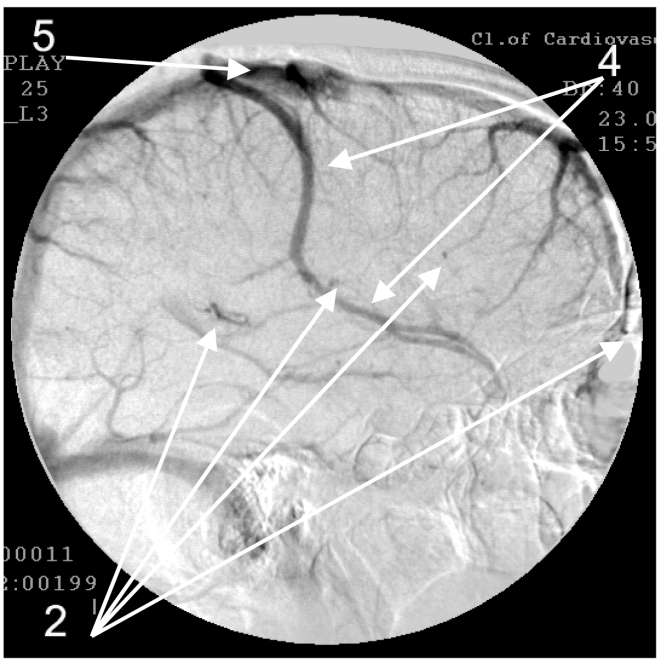

(b)

Figure 5. Angiogram of the left internal carotid artery of patient S., 42 years old (son); lateral projection, (a) arterial phase; (b) venous phase. 1: Devepment of hypovascular region; 2: Multiple arteriovenous shunts in frontoparietal and temporal regions; 3: Multiple loop formation; 4: Development of anomalous venous trunks in the frontoparietal region; 5: Development of congestion on the boundary of the frontoparietal region. 


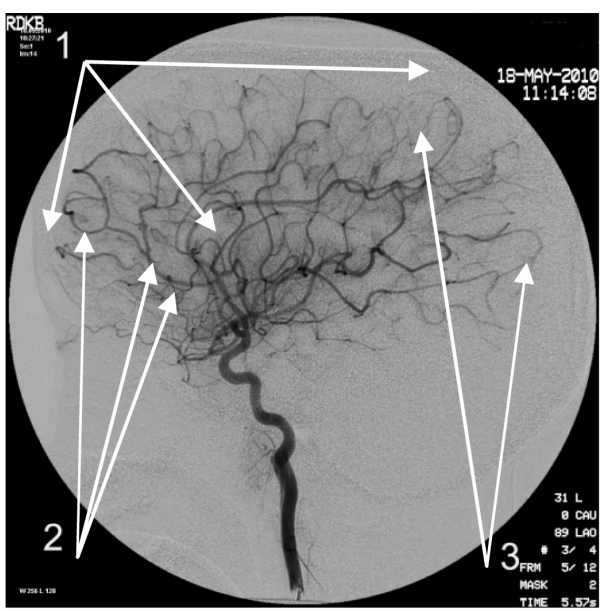

(a)

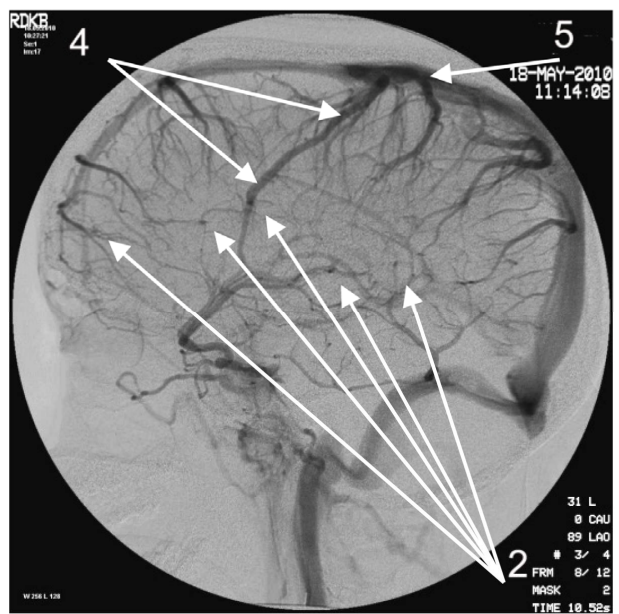

(b)

Figure 6. Angiogram of the left internal carotid artery of patient S., 10 years old (grandson); lateral projection, (a) arterial phase; (b) venous phase. 1: Development of hypovascular region; 2: Multiple arteriovenous shunts in frontoparietal and temporal regions; 3: Multiple loop formation; 4: Development of anomalous venous trunks in the frontoparietal region; 5: Development of venous stasis on theboundary of the frontoparietal region.

an early stage among the patients' descendants.

This research uses simple descriptive statistics, is of a "case study" type (takes into consideration individual cases) and does not require the use of inferential statistics methods.

\section{DISCUSSION}

The essence of vascular disorders, the vascular factor in AD or of Dyscirculatory Angiopathy of Alzheimer's Type (DAAT) $[16,18,29]$ is the degeneration and reduction of the capillary bed in the temporal and fronto-parietal region of the brain which in turn leads to the formation of multiple arteriovenous shunts in these areas. The developed arteriovenous shunts lead to early arterio-venous blood dumping resulting in the development of abnormally enlarged lateral venous trunks that receive blood from the temporal and fronto-parietal region passing by the capillaries, which in turn leads to venous stasis at the boundary of the frontal and parietal lobes [53,54].

Disorders of the capillary bed of the brain during AD are described by many authors [30-33,40,43,45].

These findings are very clearly confirmed by electron microscopy studies conducted by S. J. Baloiannis and I. S. Baloiannis in 2012 [47] who, using "Golgi silver impregnation technique", have shown degeneration and significant decrease in the number of capillaries per cubic centimeter of hippocampus tissue among patients suffering from $\mathrm{AD}$ as compared with healthy hippocampus tissue of a person of the same age (Figures 7 and 8 ).

According to our data, similar disorders of the capillary bed are observed both among patients suffering from $A D$ and among their descendants, suggesting that vascular disorders are probably primary in the development of the disease and are obviously innate as they are observed

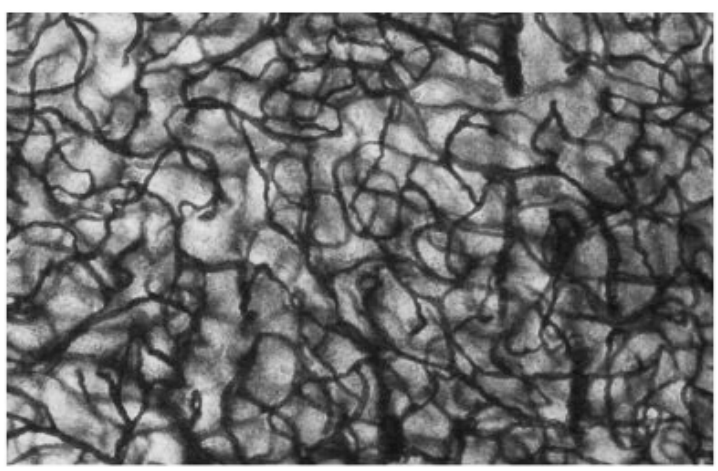

Figure 7. Baloiannis, S.J. and Baloiannis, I.S. (2012) [47]. Capillaries from the CA1 area of the hippocampus of a woman aged 72 years, neurologically intact. (Golgi staining enriched with copper chloride. 1200× Magnification).

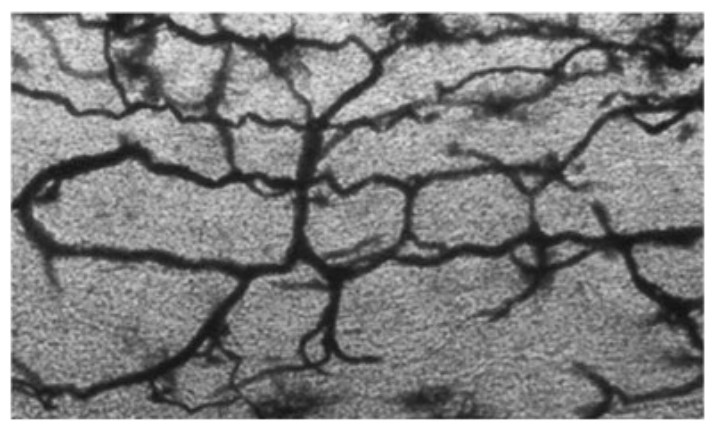

Figure 8. Baloiannis, S.J. and Baloiannis, I.S. (2012) [47]. Capillaries from the CA1 area of the hippocampus of a woman aged 72 years, neurologically intact (Golgi staining enriched with copper chloride. 1200× Magnification). 
among children of $8-12$ years old.

The data obtained during CT and MRI show that patients examined, regardless of their AD stage, have clear morphological and structural changes that are atrophic in nature and are located in the tissue of temporal as well as frontoparietal brain regions $[16,19,29,52]$. The degree of these changes increases as $\mathrm{AD}$ becomes more severe and accounts for: in AD preclinical stage TDR-0 (4\% - 8\%), in $\mathrm{AD}$ early clinical stage TDR-1 (9\% - 18\%), in AD middle clinical stage TDR-2 (19\% - 32\%) and in AD late clinical stage TDR-3 (33\% - 62\%) of atrophy of the total mass of a healthy person's temporal lobes.

It has been noted in our earlier works that similar changes in the temporal lobes do not occur among patients with other neurodegenerative diseases [16-19,29,52]; these data are also supported by other authors' works [55].

It is thus likely that atrophic changes in the temporal and fronto-parietal regions of the brain are secondary in the development of $\mathrm{AD}$ and develop against the background of existing microvascular changes which contribute to atrophy progression.

The data obtained are confirmed by other authors' studies $[43,44]$ showing experimentally that AD development in the brain is characterized by the accumulation of vasculotoxic and neurotoxic molecules causing reduction in capillary blood flow and hypoxia development, which, in turn, lead to disorders in the process of accumulation and removal of amyloid beta, which, in turn, leads to dysfunction and neurodegenerative processes.

Thus, the accumulation of amyloid in the brain, taking a long time, depends on the initial state of the microvascular bed and it also contributes to further deterioration of microcirculation.

This research shows that patients who are AD patients' descendants begin to develop at a fairly young age certain primary hypotrophic changes in the tissue of the temporal lobes of the brain against the background of disorders in microcirculation, which may indicate the development of hypoperfusion, hypoxia, and the emergence of specific signs of ischemia. That, in turn, could lead to a high probability of future disorders in the process of accumulation and removal of amyloid beta in the brain and to further $\mathrm{AD}$ development.

\section{CONCLUSIONS}

Thus, we can conclude that vascular changes and temporal lobe atrophy that develop in the brain appear long before $\mathrm{AD}$ symptoms and play an important role in the etiology and pathogenesis of the disease. The examination of $\mathrm{AD}$ patients' relatives should begin well before the possible manifestations of the disease, even in childhood. It will allow to reveal the possibility of inheritance and the signs of the disease at the earliest possible stage which is not characterized by any clinical manifestations and to begin its treatment in time. The need for an early AD patients' relatives' examination was mentioned in AAIC-2012 conclusions [56].

In recent years, for the treatment of $\mathrm{AD}$ there have mainly been developed drugs to fight amyloid deposits. According to the latest data provided by the Alzheimer's Association, clinical trials of such drugs as Solanezumab by Eli Lilly \& Co and Bapineuzumab by Pfizer \& Janssen have shown a positive trend if they are taken during early AD stages. Obviously, the working out of AD treatments should consider the impact on the microcirculatory system of the brain. The impact on brain microcirculation will clinically allow receiving not only a medicinal but also a preventive effect in the development of the disease [53].

\section{REFERENCES}

[1] 2011 Alzheimer's Disease Facts and Figures. http://www.alz.org/downloads/Facts_Figures 2011.pdf

[2] Alzheimer's Association, Generation Alzheimer's: The Defining Disease of the Baby Boomers. http://act.alz.org/site/DocServer/ALZ BoomersReport.pd f?docID $=521$

[3] Fagan, A., Xiong, C., Bateman, R., et al. (2011) Plasma and cerebrospinal fluid markers in the DIAN study of autosomal-dominant Alzheimer's disease. Journal of Alzheimer's \& Dementia, 7, S287.

http://www.alzheimersanddementia.com/article/S1552-52 60(11)00972-1/fulltext

[4] Perrin, R.J., Craig-Schapiro, R., Morris, J.C., et al. (2011) Identification and validation of novelcerebrospinal fluid biomarkers for staging early Alzheimer's disease. PLoS One, 12, e16032.

http://www.ncbi.nlm.nih.gov/pmc/articles/PMC3020224/ ?tool $=$ pmcentrez

[5] Torack, R.M. (1979) Adult dementia: History, biopsy, pathology. Neurosurgery, 4, 434-442. doi:10.1227/00006123-197905000-00011

[6] Blacker, D., Albert, M.S., Bassett, S.S., Go, R.C., Harrell, L.E. and Folstein, M.F. (1994) Reliability and validity of NINCDS-ADRDA criteria for Alzheimer's disease. The National Institute of Mental Health Genetics Initiative. Archives of Neurology, 51, 1198-2204.

http://www.ncbi.nlm.nih.gov/pubmed/7986174?dopt=Abs tract

[7] Corey-Bloom, J., Thal, L., Galasko, D., et al. (1995) Diagnosis and evaluation of dementia. Neurology, 45, 211218. http://www.ncbi.nlm.nih.gov/pubmed/7854514

[8] Tiraboschi, P., Hansen, L.A., Thal, L.J. and Corey-Bloom, J. (2004) The importance of neuritic plaques and tangles to the development and evolution of AD. Neurology, 8, 1984-1989.

http://www.ncbi.nlm.nih.gov/pubmed/15184601?dopt=A bstract

[9] Morris, J.C. (1993) The clinical dementia rating (CDR): 
Current version and scoring rules. Neurology, 11, 24122414. http://www.ncbi.nlm.nih.gov/pubmed/8232972

[10] Folstein, M.F., Folstein, S.E. and McHugh, P.R. (1975) "Mini-mental state". A practical method for grading the cognitive state of patients for the clinician. Journal of Psychiatric Research, 12, 189-198.

http://www.ncbi.nlm.nih.gov/pubmed/1202204

[11] Jack, C.R., Bentley, M.D., Twomey, C.K. and Zinsmeister, A.R. (1990) MR Imaging-based volume measurements of the hippocampal formation and anterior temporal lobe: Validation studies. Radiology, 176, 205-209.

http://www.ncbi.nlm.nih.gov/pubmed/2353093

[12] Jack, C.R., Petersen, R.C., Xu, Y.C., et al. (1997) Medial temporal atrophy on MRI in normal aging and very mild Alzheimer's disease. Neurology, 49, 786-794. http://www.ncbi.nlm.nih.gov/pubmed/9305341

[13] Saykin, A.J., Wishart, H.A., Rabin, L.A., et al. (2006) Older adults with cognitive complaints show brain atrophy similar to that of amnestic MCI. Neurology, 12, 834842. http://www.ncbi.nlm.nih.gov/pubmed/16966547

[14] Small, B.J., Gagnon, E. and Robinson, B. (2007) Early identification of cognitive deficits: Preclinical Alzheimer's disease and mild cognitive impairment. Geriatrics, 62, 19-23.

http://www.ncbi.nlm.nih.gov/pubmed/17408315

[15] Waldemar, G., Dubois, B., Emre, M., et al. (2007) Recommendations for the diagnosis and management of Alzheimer's disease and other disorders associated with dementia: EFNS guideline. European Journal of Neurology, 14, e1-e26. http://www.ncbi.nlm.nih.gov/pubmed/17222085

[16] Maksimovich, I.V. and Gotman, L.N. (2006) Method of complex radiation diagnostics at preclinical and clinical stages of Alzheimer's disease. Russian Patent No. 2315559. http://bankpatentov.ru/node/28577

[17] Maksimovich, I.V., Gotman, L.N. and Masyuk, S.M. (2006) Method of determining dimensions of temporal brain lobes in patients suffering from Alzheimer's disease. Russian Patent No. 2306102.

http://worldwide.espacenet.com/publicationDetails/biblio ?DB=EPODOC\&adjacent $=$ true\&locale $=$ en $E P \& F T=D \&$ $\underline{\text { date }}=20070920 \& C C=\mathrm{RU} \& N R=2306102 \mathrm{C} 1 \& \mathrm{KC}=\mathrm{C} 1$

[18] Maksimovich, I.V. (2008) Radiodiagnostics of Alzheimer's disease. Diagnostics and Intervention Radiology, 2, 27-38. http://www.radiology-di.ru/tom-2-N4-2008.html

[19] Maksimovich, I.V. (2009) Possibilities of modern computed tomography of brain in Alzheimer's disease diagnosis. The Neurologic Bulletin, 1, 5-10. http://www.infamed.com/nb/1 2009 5-10.pdf

[20] Chiang, G.C. Insel, Ph.S., Tosun, D., Schuff, N., TruranSacrey, D., Raptentsetsang, S., Jack, C.R. and Weiner, M.W. (2011) Identifying cognitively healthy elderly individuals with subsequent memory decline by using automated MR temporoparietal volumes. Radiology, 259, 844-851. http://radiology.rsna.org/content/259/3/844

[21] Trojanowski, J.Q., Vandeerstichele, H., Korecka, M., et al. (2010) Update on the biomarker core of the Alzheimer's disease neuroimaging initiative subjects. Journal of Alz- heimer's \& Dementia, 6, 230-238. http://www.ncbi.nlm.nih.gov/pubmed/20451871

[22] Jack, C., Vemuri, P.H., Viste, H., et al. (2011) Ordering of Alzheimer's disease biomarkers. Alzheimer's \& Dementia, 7, S4-S5. doi:10.1016/j.jalz.2011.05.011

[23] Meyer, P.T., Hellwig, S., Amtage, F., et al. (2011) Dualbiomarker imaging of regional cerebral amyloid load and neuronal activity in dementia with PET and 11C-labeled Pittsburgh compound B. Journal of Nuclear Medicine, 52, 393-400. http://www.ncbi.nlm.nih.gov/pubmed/21321269

[24] Adriaase, A., Sanz-Arigita, E., Binnewijzend, M., et al. (2011) Molecular markers of Alzheimer's disease pathology and their relationship with default mode network integrity. Journal of Alzheimer's \& Dementia, 7, S2-S3. http://www.alzheimersanddementia.com/article/S1552-52 $\underline{60(11) 00144-0 / \text { fulltext }}$

[25] Chételat, G., Villemagne, V.L., Pike, K.E., Ellis, K.A., Ames, D., Masters, C.L. and Rowe, C.C. (2012) Relationship between memory performance and $\beta$-amyloid deposition at different stages of Alzheimer's disease. Neurodegenerative Diseases, 10, 141-144. http://www.ncbi.nlm.nih.gov/pubmed/22301812

[26] Holmes, C., Boche, D., Wilkinson, D., et al. (2008) Longterm effects of Abeta42 immunisation in Alzheimer's disease: Follow-up of a randomised, placebo-controlled phase I trial. The Lancet, 372, 216-223.

http://www.ncbi.nlm.nih.gov/pubmed/18640458?dopt=A $\underline{\text { bstract }}$

[27] Morel, F. (1950) An apparently dyshoric and topical angiopathy. Monatsschrift for Psychiatrie Neurologie, 120, 352-357. http://www.ncbi.nlm.nih.gov/pubmed/14806299

[28] Maksimovich, I.V. (2009) Changes in angioarchetectonics of brain at Alzheimer's disease. The Neurologic Bulletin, 2, 9-14. http://www.infamed.com/nb/2 2009 9-14.pdf

[29] Maksimovich, I.V. (2011) Dyscirculatory angiopathy of Alzheimer's type. Journal of Behavioral and Brain Science, 1, 57-68. doi:10.4236/jbbs.2011.12008

[30] de la Torre, J.C. (1997) Hemodynamic consequences of deformed microvessels in the brain in Alzheimer's disease. Annals of New York Acadmy Sciences, 26, 75-91. http://www.ncbi.nlm.nih.gov/pubmed/9329682?dopt=Abs tract

[31] Skoog, I., Kalaria, R.N. and Breteler, M.M. (1999) Vascular factors and Alzheimer disease. Alzheimer Disease and Associated Disorders, 13, 106-114.

http://www.ncbi.nlm.nih.gov/pubmed?term=Skoog\%20I $\% 2 \mathrm{C} \% 20$ Kalaria $\% 20 \mathrm{R} \% 20 \mathrm{~N} \% 2 \mathrm{C} \% 20$ Breteler $\% 20 \mathrm{M} . \mathrm{M}$.

[32] Kalaria, R.N. (2000) Vascular factors in Alzheimer's disease. New York Academy of Sciences, New York. http://books.google.ru/books?id=jHZFAAAAYAAJ\&hl=r u\&source $=\mathrm{gbs}$ book similarbooks

[33] Kivipelto, M., Helkala, E.L., Laakso, M.P., et al. (2001) Midlife vascular risk factors and Alzheimer's disease in later life: Longitudinal, population based study. British Medical Journal, 322, 1447-1451. http://www.bmj.com/content/322/7300/1447

[34] Kalaria, R.N. (2009) Neurodegenerative disease: Diabetes, microvascular pathology and Alzheimer disease. Nature 
Reviews. Neurology, 5, 305-306. http://www.ncbi.nlm.nih.gov/pubmed/19498432

[35] Di Iorio, A., Zito, M., Lupinetti, M. and Abate, G. (1999) Are vascular factors involved in Alzheimer's disease? Facts and theories. Aging, 11, 345-352. http://www.ncbi.nlm.nih.gov/pubmed/10738848

[36] Mielke, M.M., Rosenberg, P.B., Tschanz, J.L., Cook, L., et al. (2007) Vascular factors predict rate of progresssion in Alzheimer disease. Neurology, 6, 1850-1858. http://www.neurology.org/content/69/19/1850.short

[37] Helzner, E.P., Luchsinger, J.A., Scarmeas, N., Cosentino, S., et al. (2009) Contribution of vascular risk factors to the progression in Alzheimer disease. Archives of Neurology, 66, 343-348. doi:10.1001/archneur.66.3.343

[38] Weller, R.O., Subash, M., Preston, S.D., Mazanti, I. and Carare, R.O. (2008) Perivascular drainage of amyloidbeta peptides from the brain and its failure in cerebral amyloid angiopathy and Alzheimer's disease. Brain Pathology, 18, 253-266.

http://www.ncbi.nlm.nih.gov/pubmed/18363936

[39] Pezzini, A., Del Zotto, E., Volonghi, I., Giossi, A., Costa, P. and Padovani, A. (2009) Cerebral amyloid angiopathy: A common cause of cerebral hemorrhage. Current Medicinal Chemistry, 16, 2498-2513. doi:10.2174/092986709788682047

[40] de la Torre, J.C. and Stefano, G.B. (2000) Evidence that Alzheimer's disease is a microvascular disorder: The role of constitutive nitric oxide. Brain Research Reviews, 34, 119-136. doi:10.1016/S0165-0173(00)00043-6

[41] Kalaria, R.N. (2002) Small vessel disease and Alzheimer's dementia: Pathological considerations. Cerebrovascular Diseases, 13, 48-52. doi:10.1159/000049150

[42] de la Torre, J.C. (2002) Alzheimer disease as a vascular disorder: Nosological evidence. Stroke, 33, 1152-1162. doi:10.1161/01.STR.0000014421.15948.67

[43] Bell, R.D. and Zlokovic, B.V. (2009) Neurovascular mechanisms and blood-brain barrier disorder in Alzheimer's disease. Acta Neuropathologica, 118, 103-113. http://www.ncbi.nlm.nih.gov/pubmed/19319544

[44] Zlokovic, B.V. (2011) Neurovascular pathways to neurodegeneration in Alzheimer's disease and other disorders. Nature Reviews. Neuroscience, 3, 723-738. http://www.ncbi.nlm.nih.gov/pubmed/22048062

[45] De la Torre, J.C. (2012) A turning point for Alzheimer's disease? Biofactors, 38, 78-83. doi:10.1002/biof.200

[46] Dhikav, V. and Anand, K.S. (2012) Are vascular factors linked to the development of hippocampal atrophy in Alzheimer's disease? Journal of Alzheimer's Disease, 32,
711-718. http://www.ncbi.nlm.nih.gov/pubmed/22850312

[47] Baloiannis, S.J. and Baloiannis, I.S. (2012) The vascular factor in Alzheimer's disease: A study in Golgi technique and electron microscopy. Journal of the Neurological Sciences, 322, 117-121.

http://www.jns-journal.com/article/S0022-510X(12)0034 4-9/abstract

[48] Sagare, A.P., Bell, R.D. and Zlokovic, B.V. (2012) Neurovascular defects and faulty amyloid- $\beta$ vascular clearance in Alzheimer's disease. Journal of Alzheimer's disease, 2, a011452. http://www.ncbi.nlm.nih.gov/pubmed/22751174

[49] Kalaria, R.N., Akinyemi, R. and Ihara, M. (2012) Does vascular pathology contribute to Alzheimer changes? Journal of the Neurological Sciences, 322, 141-147. http://www.ncbi.nlm.nih.gov/pubmed/22884479

[50] Kalaria, R. (2012) The neuropathology of vascular cognitive disorders. Journal of Alzheimer's \& Dementia, 8, P727. doi:10.1016/j.jalz.2012.05.1958

[51] Maksimovich, I.V. and Polyaev, Yu.A. (2010) The importance of early diagnosis of dyscircular angiopathy of Alzheimer's type in the study of heredity of Alzheimer's disease. Journal of Alzheimer's \& Dementia, 6, e43.

http://www.alzheimersanddementia.com/article/S1552-52 60(10)02325-3/fulltext

[52] Maksimovich, I.V. (2012) The tomography dementia rating scale (TDR) - The rating scale of Alzheimer's disease stages. Health, 4, 712-719.

http://www.scirp.org/journal/PaperInformation.aspx?pape $\underline{\mathrm{rID}}=23257$

[53] Maksimovich, I.V. (2012) Vascular factors in Alzheimer's disease. Health, 4, 735-742.

http://www.scirp.org/journal/PaperInformation.aspx?pape $\underline{\mathrm{rID}=23274}$

[54] Maksimovich, I.V. (2012) Endovascular application of low-energy laser in the treatment of dyscirculatory angiopathy of Alzheimer's type. Journal of Behavioral and Brain Science, 2, 67-81. doi:10.4236/jbbs.2012.21008

[55] Burton, E.J., Barber, R., Mukaetova-Ladinska, E.B., Robson, J., Perry, R.H., Jaros, E., Kalaria, R.N. and O'Brien, T.J. (2009) Medial temporal lobe atrophy on MRI differentiates Alzheimer's disease from dementia with lewy bodies and vascular cognitive impairment: A prospective study with pathological verification of diagnosis. Brain, 132, 195-203.

http://www.ncbi.nlm.nih.gov/pubmed/19022858

[56] World Alzheimer's Report 2012. http://www.alz.org/documents custom/world report 201 2 final.pdf 